\title{
An update of the factors showing cigarette smoking as an etiologic factor of the ischemic heart disease
}

\section{Editorial}

A large majority of pathologists look their research as the most important field of the medical science. Indeed, evidence indicates that cardiovascular pathology has a significant role for what concern both epidemiology and both heart and blood vessel disease. ${ }^{1}$

Studies show the high incidence of cardiovascular events primarily related to ischemic heart disease and its association with coronary risk factors. ${ }^{2-4}$ Undoubtedly, cigarette smoking plays a preminent role in developing either myocardial or coronary vessel harm. ${ }^{5-7}$

Epidemiological survey usually conducted by the analisys of cohort studies, case-control studies, metanalisys and pathological findings permitted to define that an adverse relationship exists between cigarette smoking, either active or passive smoking, and cardiovascular system. ${ }^{8-10}$

Years after years the type of harm caused by cigarette smoking on the heart and blood vessel, primarily with regard to ischemic heart pathology, has been well established.

Carbon monoxide and nicotine are the main compounds of smoking able to harm cardiovascular system. Carbon monoxide acts chronically causing, in the time, myocardial and coronary vessel lesions, which after continuous and prolonged exposure, become irreversible alterations. On the contrary, nicotine causes primarily a functional and reversible damage to the heart and coronary vessels in both active smokers and individuals passively exposed to tobacco smoking. ${ }^{11,12}$ However, an irreversible harm is the final result of nicotine effects. Therefore, evidence indicates that both these chemicals determine either acute or chronic type of damage to cardiovascular system. The observations briefly reported permit to identify that some factors due to smoking exposure play a strong role in determining both myocardial and coronary vessel alterations, which are clearly associated with the development of ischemic heart disease.

First, the toxic effects of carbon monoxide and nicotine on cardiovascular system have been undoubtedly documented by a great number of reports. Secondly, the development of pathological alterations, which are similar in the large majority of individuals exposed to smoking, when they suffer from an ischemic heart disease, cannot be denied. Thirdly, the toxicity of carbon monoxide and nicotine in those individuals exposed to these chemicals even in absence of cigarette smoking affects several body organs primarily heart and respiratory system.

In conclusion, some compounds of smoking always damage cardiovascular system either acutely or in the long run and, therefore, cigarette smoking should be classified as an etiologic factor of ischemic heart disease. ${ }^{13}$ Exposure to both active and passive smoking is strongly deleterious with regard to the fact that other cardiovascular risk factors as hypertension, lipid disorders, obesity and metabolic syndrome strengthen smoking toxicity.

\section{Acknowledgments}

None.
Volume 14 Issue 6 - 202 I

\author{
Aurelio Leone \\ Fellow of the Royal Society for Promotion of Health (FRSPH), \\ UK
}

Correspondence: Aurelio Leone, Fellow of the Royal Society for Promotion of Health (FRSPH), Fellow of the American Heart Association (FAHA), UK, Tel +393472272215,

Email reliol@libero.it

Received: November 16, 2021 | Published: November 23, 2021

\section{Conflicts of interest}

No conflict of interest.

\section{Funding}

None.

\section{References}

1. Leone A. Cigarette smoking and health of the heart. $J$ Roy Soc Health. 1995;115 (6):354-355.

2. Leone A. Relationship between cigarette smoking and other coronary risk factors in atherosclerosis:Risk of cardiovascular disease and preventive measures. Curr Pharm Des. 2003;9(29):2417-2423.

3. White HD, Chew DP. Acute myocardial infarction. Lancet 2008;372(9638):570-584.

4. Eliot RS, Baroldi G, Leone A. Necropsy studies in myocardial infarction with minimal or no coronary luminal reduction due to atherosclerosis. Circulation. 1974;49 (86):1127-1131.

5. Leone A. Myocardial infarction.Pathological relevance and relationship with coronary risk factors. Curr Pharm Des. 2017;23(22):3205-3216.

6. Ockene IS, Houston Miller N. Cigarette smoking, cardiovascular disease and stroke:a statement for healthcare professionals from the American Heart Association. American Heart Association Task Force on Risk Reduction. Circulation. 1997;96(9):3243-3247.

7. Leone A, Landini L Jr, Biadi O, et al. Smoking and cardiovascular system:Cellular features of the damage. Curr Pharm Des. 2008;14(18):1771-1777.

8. Helsing KJ, Sandler DP, Comstock GW, et al. Heart disease mortality in nonsmokers living with smokers. Am J Epidemiol. 1988;127(5):915-922.

9. Garland C, Barret-Connor E, Suarez L, et al. Effects of passive smoking on ischemic heart disease mortality of nonsmokers:a prospective study. Am J Epidemiol. 1985;121(5):645-650.

10. Hole DJ, Gillis CR, Chopra C, et al. Passive smoking and cardiorespiratory health in a general population in the west of Scotland. BMJ. 1989;299(6696):423-427. 
11. Leone A. Cardiovascular damage from smoking:a fact or belief? Int $J$ Cardiol. 1993;38(2):113-117.

12. Leone A, Mori L, Bertanelli F, et al. Indoor passive smoking:Its effect on cardiac performance. Int J Cardiol. 1991;33(2):247-252.
13. Leone A. Should smoke exposure be considered an etiologic factor for cardiovascular disease? Future Sci OA. 2016;2(1):FS094. 